\title{
Cathodoluminescence and microRaman analysis of oxygen loss in electron irradiated $\mathrm{YBa}_{2} \mathrm{Cu}_{3} \mathrm{O}_{7-x}$
}

\author{
P. Gómez ${ }^{a)}$ \\ Departamento de Física de Física de Materiales, Facultad de Física, Universidad Complutense, \\ 28040-Madrid, Spain and Departamento de Fisica Aplicada, E.U.I.T.A., Universidad de Castilla-La \\ Mancha, 13071-Ciudad Real, Spain
}

J. Jiménez and P. Martin

Departamento de Fisica de la Materia Condensada, ETS Ingenieros Industriales, 47011-Valladolid, Spain

J. Piqueras and F. Dominguez-Adame

Departamento de Física de Materiales, Facultad de Fisica, Universidad Complutense, 28040-Madrid, Spain

(Received 9 April 1993; accepted for publication 16 July 1993)

\begin{abstract}
The effect of oxygen loss on the luminescence of $\mathrm{YBa}_{2} \mathrm{Cu}_{3} \mathrm{O}_{7-x}$ has been investigated by cathodoluminescence (CL) in the scanning electron microscope (SEM) and by Raman microprobe measurements. The results herein indicate that a CL band at $530 \mathrm{~nm}$ is related to oxygen loss rather than to impurity phases such as $\mathrm{Y}_{2} \mathrm{O}_{3}$ formed in the material by electron irradiation in the SEM.
\end{abstract}

\section{INTRODUCTION}

Cathodoluminescence (CL) signal of $\mathrm{YBa}_{2} \mathrm{Cu}_{3} \mathrm{O}_{7-x}$ (YBCO) increases during electron irradiation in the scanning electron microscope. ${ }^{1,2}$ The evolution of the CL intensity and spectra under an electron beam has been described elsewhere. ${ }^{2}$ This effect, which enables one to generate localized luminescent regions in YBCO, has been attributed to structural changes caused by electroninduced oxygen loss. In the present work this possibility is further investigated. For this purpose the oxygen content in electron irradiated regions of $\mathrm{YBCO}$ has been compared with that in unirradiated regions by means of microRaman measurements and the CL emission in the same samples has been measured. On the other hand, the CL behavior of the samples irradiated in the electron microscope has been compared with that of samples undergoing other treatments causing oxygen loss, such as laser irradiation or vacuum annealing.

\section{EXPERIMENTAL METHOD}

The samples were sintered $\mathrm{YBa}_{2} \mathrm{Cu}_{3} \mathrm{O}_{7-x}$ with nominal $T_{c}$ values of $93 \mathrm{~K}$. Well-defined regions of a sample were electron irradiated at $30 \mathrm{keV}$ in the scanning electron microscope (SEM) by performing a repetitive scan line. The irradiated line was identified in the emisive mode image by the appearance of a rough surface in a region about $10 \mu \mathrm{m}$ wide.

MicroRaman measurements were performed at different points along a line perpendicular to the irradiated line. The excitation was done with the $514.5 \mathrm{~nm}$ line of an $\mathrm{Ar}^{+}$ laser through a $100 \times$ microscope objective with a large numerical aperture $(\mathrm{NA}=0.950)$. The laser spot at the focal plane had a diameter smaller than $1 \mu \mathrm{m}$, which is the lateral resolution of the Raman microprobe. Both the excitation and the light collection were done through the microscope objective, hence the measurement geometry was backscattering. The Raman spectrometer was a
DILOR $X Y$ equipped with multichannel detection. The laser power density was low enough to avoid local heating that might damage the sample. The sample was mounted on a motorized $X-Y$ stage that allows high precision regularly spaced point by point Raman measurements. All measurements were carried out at room temperature and no special preparation of the sample was required.

Other samples were annealed at $10^{-2}$ Torr at temperatures between 100 and $500^{\circ} \mathrm{C}$ for $20 \mathrm{~h}$ or irradiated at $10^{-2}$ Torr with a multiwavelength $\mathrm{Ar}$ ion laser. Luminescence of treated and untreated samples was measured in the SEM with a previously described experimental arrangement. ${ }^{3}$

\section{RESULTS AND DISCUSSION}

In general, untreated samples show a low $\mathrm{CL}$ emission that becomes readily detectable after a certain observation time in the SEM due to electron irradiation. For this reason CL spectra of nominally untreated samples are often modified by the electron irradiation. However, spectra recorded at the first stage of observation indicate that the CL emission of untreated samples is mainly related to a band in the $400-450 \mathrm{~nm}$ region. This agrees with the observation of Stankevich et al. ${ }^{4}$ that a band at $440 \mathrm{~nm}$ is inherent to $\mathrm{YBa}_{2} \mathrm{Cu}_{3} \mathrm{O}_{7-x}$ crystals. Figure 1 shows the $\mathrm{CL}$ image of the electron irradiated line and Fig. 2 the corresponding CL spectrum of this region. The spectrum shows a band in the $500-550 \mathrm{~nm}$ spectral range previously associated to electron beam effects. The width of the luminescent region is not constant along the line and ranges between 15 and about $20 \mu \mathrm{m}$.

Figure 3 shows the Raman spectra obtained at different points along a line crossing the electron irradiated region. An optical microscopy (Nomarsky) inspection reveals a highly damaged region $(\sim 10 \mu \mathrm{m}$ wide), surrounded by a slightly damaged region, which extends about $10-15 \mu \mathrm{m}$ out of the damaged region. These areas 


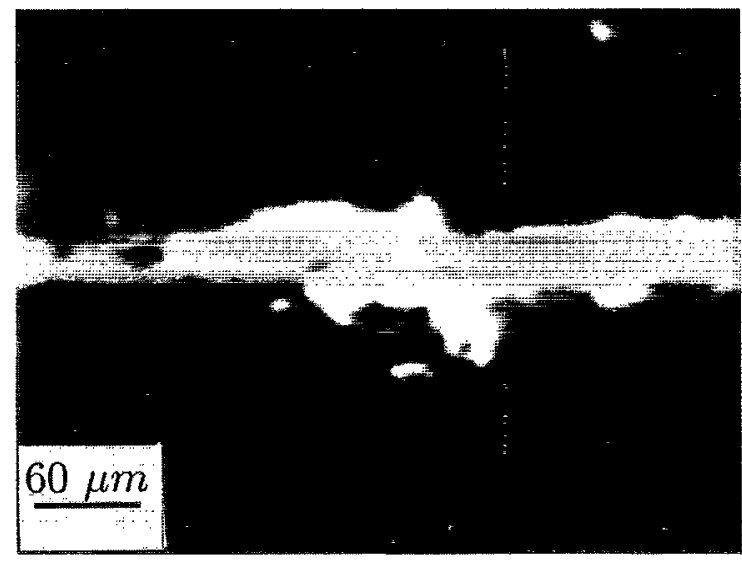

FIG. 1. CL image from an electron irradiated line.

correspond to those seen by CL imaging and will be henceforth labeled as undamaged region, slightly damaged region and heavily damaged region respectively.

The spectrum obtained in the undamaged region is according to the Raman scattering selection rules typical of the $c \|$ oriented crystals, which give a spectrum characterized by a strong peak at $\sim 500 \mathrm{~cm}^{-1}$, associated to the stretching of the bridging oxygen. ${ }^{5}$ The peak at $335 \mathrm{~cm}^{-1}$ is practically unobservable in this scattering configuration and is associated with in-plane $\mathrm{CuO}_{2}$ oxygen vibrations out of phase. ${ }^{5}$ The frequency shift of the $500 \mathrm{~cm}^{-1}$ peak allows the oxygen content of the $\mathrm{YBa}_{2} \mathrm{Cu}_{3} \mathrm{O}_{7-x}$ crystals to be assessed. $^{6-8}$ As the region surrounding the electron irradiated area, previously identified as the slightly damaged region, is probed by the laser beam a downward frequency shift of the $500 \mathrm{~cm}^{-1}$ peak is observed; together with this frequency softening an increase of the $I(335) / I(500)$ intensity ratio is seen. All that provides clear evidence of the oxygen decrease in this slightly damaged region. ${ }^{6,7}$ Figure 4 shows the frequency shift of the $500 \mathrm{~cm}^{-1}$ peak as a function of the position along the scanning line.

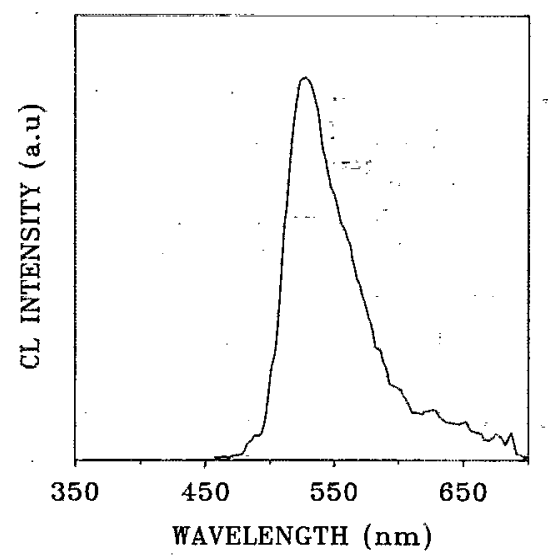

FIG. 2. CL spectrum from the same electron irradiated line shown in Fig. 1.

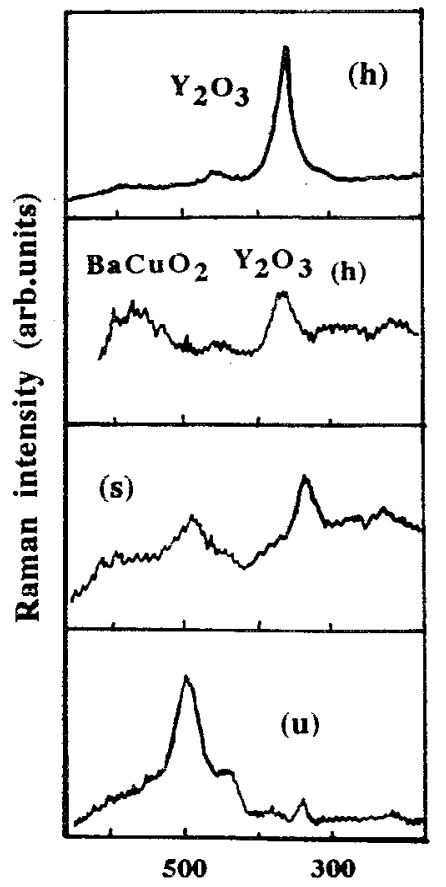

Raman frequency $\left(\mathrm{cm}^{-1}\right)$

FIG. 3. Raman spectra obtained at different points of the undamaged region $(u)$, slightly damaged region (s), and heavily damaged region (h).

When the laser beam probes the heavily damaged region the Raman spectrum becomes very noisy, showing a strong oxygen loss (large $x$ ) and the local formation of impurity phases, mainly oxides, at different points of the irradiated area. The frequency shift of the $335 \mathrm{~cm}^{-1}$ peak is shown as a function of position in Fig. 5; in both the undamaged and the slightly damaged regions it corresponds to $\mathrm{YBa}_{2} \mathrm{Cu}_{3} \mathrm{O}_{7-x}$ with different oxygen content. Raman spectroscopy can be used to determine the oxygen content of YBCO. In fact, the frequency of the $500 \mathrm{~cm}^{-1}$ Raman peak is strongly sensitive to the oxygen content; it

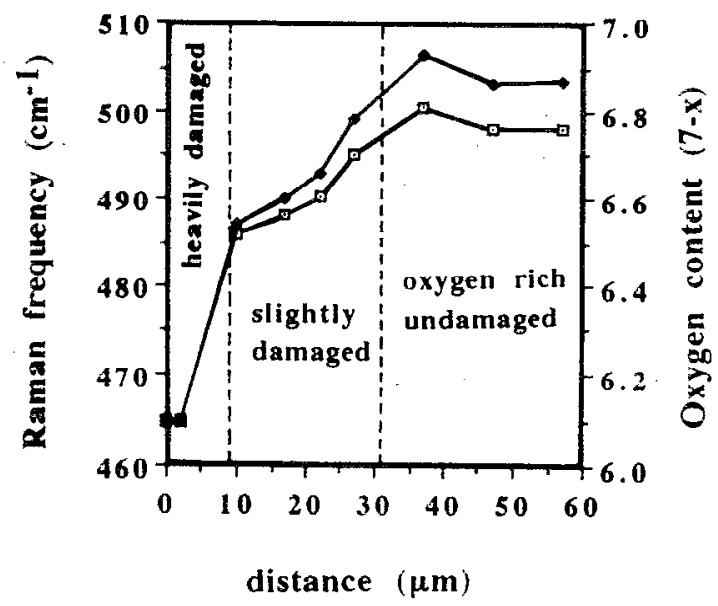

FIG. 4. Frequency of the $500 \mathrm{~cm}^{-1}$ Raman band across the scanning line. Oxygen content estimated from the frequency shift of the $500 \mathrm{~cm}^{-1}$ Raman peak. 


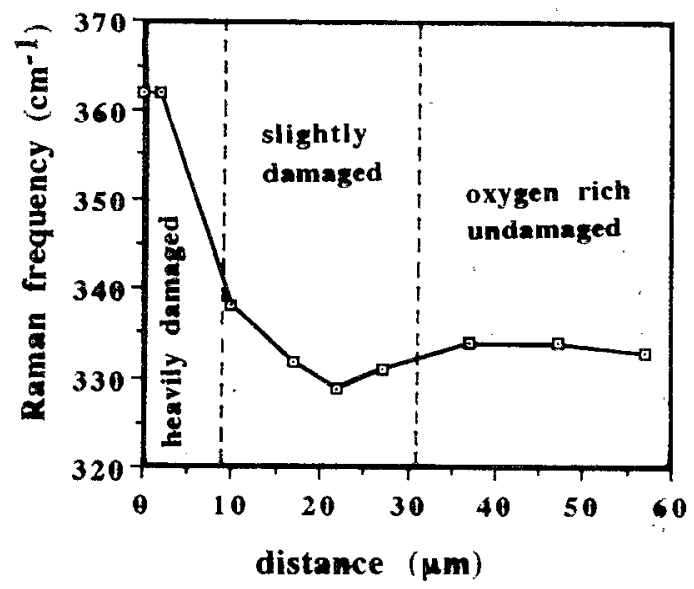

FIG. 5. Frequency of the $335 \mathrm{~cm}^{-1}$ Raman band across the scanning line. Inside the heavily damaged region appear at localized points the $\mathrm{Y}_{2} \mathrm{O}_{3}$ related band.

is downward shifted as the oxygen concentration is depressed. Thus, Raman spectroscopy is an established, nondestructive tool for determining the oxygen composition in YBCO. The estimated oxygen content is plotted as a function of the distance along the scanning line in Fig. 4 according to the following relationship ${ }^{8}$

$$
x=0.027 v(500)-6.58 \text {. }
$$

Inside the heavily damaged region this peak is significantly shifted to the blue. Such a shift cannot be accounted for by the disorder induced by the electron irradiation in the YBCO lattice; disorder could activate vibration modes which are initially Raman forbidden, nevertheless no infrared modes are seen in YBCO in this frequency range. ${ }^{9}$ On the other hand, for extreme oxygen loss the frequency shift reported for the $335 \mathrm{~cm}^{-1}$ peak is much smaller than that measured herein. ${ }^{7}$ For this reason, the $360 \mathrm{~cm}^{-1}$ peak measured at local points of the damaged region is probably associated with the formation of the $\mathrm{Y}_{2} \mathrm{O}_{3}$ impurily phase, which presents a similar Raman spectrum with a strong peak at this frequency. ${ }^{10}$ The formation of impurity phases in localized points of this region is confirmed by the identification of the $\mathrm{BaCuO}_{2}$ phase, which is identified through the Raman peaks at 575 and $640 \mathrm{~cm}^{-1} \cdot{ }^{11}$ It should be noted that the Raman cross section of these phases is much larger than the Raman cross section for the YBCO, ${ }^{11}$ therefore, no big quantities of these phases are expected from the Raman intensity measured. Anyway, the observation of these phases is not regular along the heavily damaged region, but it is rather localized at particular points. The presence of impurity phases in high $T_{c}$ YBCO is usually reported to occur at the intergrain regions; ${ }^{11}$ the most generally observed phases due to the sintering procedure are the green phase, $\mathrm{Y}_{2} \mathrm{CuO}_{5}$ and $\mathrm{BaCuO}_{2}$. No $\mathrm{Y}_{2} \mathrm{O}_{3}$ was observed in the many examined samples, both thin films or ceramics, out of the damaged area. The formation of impurity phases as a result of different treatments is usually observed, i.e., laser ablation ${ }^{12}$ and ion irradiation. ${ }^{13}$ The results we present herein support the formation of these

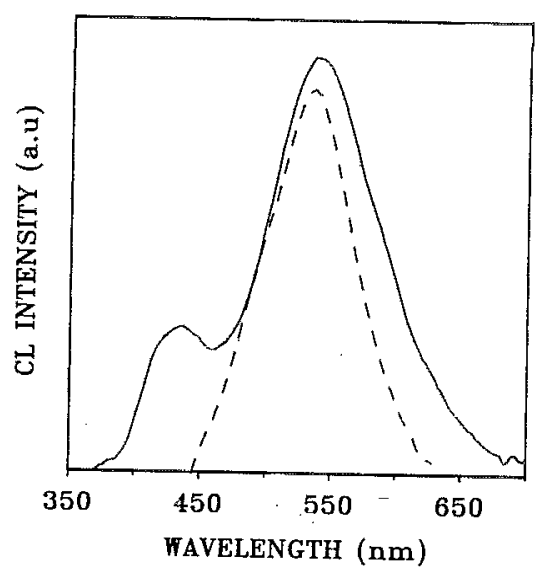

FIG. 6. CL spectra from samples' after weak (solid line) and strong (dashed line) treatments.

phases by electron irradiation as well. The fact that these phases are observed at localized point of the irradiated area could be associated with a gettering at special points, probably intergrains, where the temperature during irradiation is expected to be significantly enhanced.

The present Raman microprobe measurements reveal oxygen loss and the formation of impurity phases at localized points. This is consistent with CL measurements that associate the light emission at $530 \mathrm{~nm}$ with oxygen depletion rather than with $\mathrm{Y}_{2} \mathrm{O}_{3}$ which could account for local $\mathrm{CL}$ emission. $\mathrm{Y}_{2} \mathrm{O}_{3}$ is characterized by a strong $365 \mathrm{~nm}$ luminescence emission at low temperature ${ }^{14,15}$ which is not seen in our measurements. In order to get insight about this point we are doing similar measurements in samples prepared with different oxygen content without electron irradiation.

Similar to electron irradiation, laser irradiation produces a rough surface and enhanced $C L$ emission in the irradiated area. Laser irradiation as well as annealing treatments cause different $\mathrm{CL}$ spectra that can be qualitatively represented by the spectra of Fig. 6 . After short laser irradiation or low- $\left(200^{\circ} \mathrm{C}\right)$ temperature annealing the spectrum shown by the solid line is obtained while longer irradiation times or higher- $\left(400^{\circ} \mathrm{C}\right)$ temperature annealing produce the spectrum shown by the dashed line. It appears that all treatments cause the appearance of a luminescence band at $530 \mathrm{~nm}$. After moderate treatments the intrinsic $440 \mathrm{~nm}$ emission is still detectable but after more severe treatments the increase of the $530 \mathrm{~nm}$ emission mask the $440 \mathrm{~nm}$ band. This result shows that laser irradiation or vacuum annealing have similar effect on luminescence from $\mathrm{YBa}_{2} \mathrm{Cu}_{3} \mathrm{O}_{7-x}$ to that of the electron irradiation. The annealing and laser irradiation treatments undergone by our samples are known ${ }^{16,17}$ to produce oxygen depletion. This indicates that the $530 \mathrm{~nm} \mathrm{CL}$ emission is associated with oxygen depleted zones, but cannot be associated, with the available data, to specific defects in the material.

Since CL appears to be sensitive to structural changes in $\mathrm{YBa}_{2} \mathrm{Cu}_{3} \mathrm{O}_{7-x}$, the dependence of $\mathrm{CL}$ intensity on temperature could in some cases be used to detect specific 


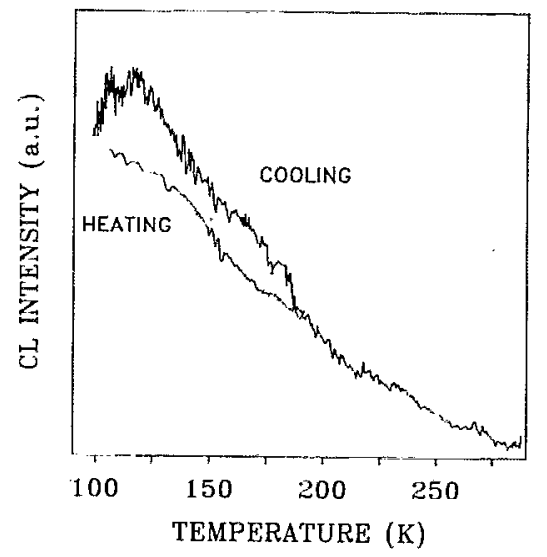

FIG. 7. Temperature dependence of CL intensity in a sample after laser irradiation trcatmcnt.

changes. This possibility, supported by previous results on high-temperature superconductor films, ${ }^{18}$ has also been studied in this work. Figure 7 shows the temperature dependence of $\mathrm{CL}$ intensity in a sample after laser irradiation treatment. A hysteretic behavior in heating and cooling runs has been observed by several authors in the measurements of acoustic properties of $\mathrm{YBCO}^{19-21}$ and has been sometimes attributed to fine structural transitions involving reordering of oxygen atoms or vacancies. It is suggested that CL evolution could reflect some of these changes.

\section{CONCLUSIONS}

Electron irradiation in the SEM causes the appearance of a CL emission band at about $530 \mathrm{~nm}$. Raman microprobe measurements reveal oxygen loss and formation of impurity phases, such as $\mathrm{Y}_{2} \mathrm{O}_{3}$ and $\mathrm{BaCuO}_{2}$, at localized points. These observations indicate that the mentioned $\mathrm{CL}$ emission is associated with oxygen depletion rather than with the presence of an extended $\mathrm{Y}_{2} \mathrm{O}_{3}$ dielectric phase.

\section{ACKNOWLEDGMENTS}

This work was partially supported by DGICYT (Project PB 90-1017). The help of Dr. J. A. García and Dr. A. Remón is acknowledged.

${ }^{1}$ J. H. Miller, D. J. Hunn, S. L. Holder, and A. N. DiBianca, Appl. Phys. Lett. 56, 89 (1990).

${ }^{2}$ J. Piqueras, P. Fernández, and J. L. Vicent, Appl. Phys. Lett. 57, 2722 (1990).

${ }^{3}$ B. Méndez and J. Piqueras, J. Appl. Phys. 69, 2776 (1991).

${ }^{4}$ V. G. Stankevich, N. Yu. Svechnikov, K. V. Kaznacheev, R. A. Kink, I. L. Kuusmann, E. Kh. Feldbach, G. Zimmerer, T. Kloiber, A. A. Zhokhov, G. A. Emel'chenko, M. A. Kalyagin, and V. Ya. Kosyev, J. Lumin. 48/49, 845 (1991).

${ }^{5}$ C. Thomsen, M. Cardona, and R. Liu, J. Less Common Metals 150, 33 (1989).

${ }^{6}$ G. Burns, F. H. Dacol, and F. Holtzberg, Solid State Commun. 75, 893 (1990).

${ }^{7}$ G. Burns, F. H. Dacol, and F. Holtzberg, Solid State Commun. 77, 367 (1991).

${ }^{8}$ Phan V. Huong, J. C. Bniyère, F. Bustarret, and P. Grandchamp, Solid State Commun. 72, 191 (1989).

${ }^{9}$ J. Chrzanowski, S. Gygax, J. C. Irvin, and W. N. Hardy, Solid State Commun. 65, 139 (1988).

${ }^{10}$ R. Bhadra, T. O. Brun, M. A. Beno, B. Dabrowski, D. G. Hinks, J. Z. Liu, J. D. Jorgensen, L. J. Nowicki, A. P. Paulickas, I. K. Schuller, C. U. Segre, L. Soderholm, B. Veal, H. H. Wang, J. M. Willians, K. Zhang, and M. Grimsditch, Phys. Rev. B 37, 5142 (1988).

"A. Erle, S. Blumenroder, E. Zirngielb, and G. Guntherodt, Solid State Commun. 73, 753 (1990).

12 J. Jiménez (unpublished).

${ }^{13}$ M. V. Belousov, F. A. Chudnovskii, V. Y. Davidov, B. S. Elkin, S. L. Shokhor, and V. Y. Velichko, Solid State Commun. 81, 493 (1992).

${ }^{14}$ W. Hayes, M. J. Kane, O. Salminen, and A. I. Kuznetsov, J. Phys. C 17, L383 (1984).

${ }^{15}$ V. V. Mürk, A. I. Kuznetsov, and B. R. Namozov, Phys. Status Solidi A 63, K131 (1981).

${ }^{16}$ S. Matsui, T. Ichihashi, T. Yoshitake, S. Miura, T. Satoh, and M. Mito, J. Vac. Sci. Technol. B 8, 1771 (1990).

${ }^{17}$ Y. Q. Shen, T. Freltoft, and P. Vase, Appl. Phys. Lett. 59, 1365 (1991).

${ }^{18}$ F. Domínguez-Adame, P. Fernández, J. Piqueras, P. Prieto, C. Barrero, and M. E. Gómez, J. Appl. Phys. 71, 2778 (1992).

${ }^{19}$ V. Müller, C. Hucho, K. de Groot, D. Winau, D. Maurer, and K. H. Ricder, Solid State Commun. 72, 997 (1989).

${ }^{20} \mathrm{O}$. Yu. Sersobol'skaya, S. P. Tokmakova, and L. A. Chernozatonskii, Sov. Phys. Solid State 33, 1209 (1991).

${ }^{21}$ L. N. Pal-val, P. P. Pal-val, V. D. Natsik, and V. I. Dotsenko, Solid State Commun. 81, 761 (1992). 
Journal of Applied Physics is copyrighted by the American Institute of Physics (AIP). Redistribution of journal material is subject to the AIP online journal license and/or AIP copyright. For more information, see http://ojps.aip.org/japo/japcr/jsp

Copyright of Journal of Applied Physics is the property of American Institute of Physics and its content may not be copied or emailed to multiple sites or posted to a listserv without the copyright holder's express written permission. However, users may print, download, or email articles for individual use. 
Journal of Applied Physics is copyrighted by the American Institute of Physics (AIP). Redistribution of journal material is subject to the AIP online journal license and/or AIP copyright. For more information, see http://ojps.aip.org/japo/japcr/jsp 